\section{Commercial Seed Lots Exhibit Reduced Seed Dormancy in Comparison to Wild Seed Lots of Echinacea purpurea}

\author{
Luping Qu, Xiping Wang, ${ }^{1}$ Ying Chen, and Richard Scalzo \\ Gaia Herbs, Inc., 108 Island Ford Road, Brevard, NC 28712
}

\begin{abstract}
Mark P. Widrlechner
U.S. Department of Agriculture, Agricultural Research Service, North Central Regional Plant Introduction Station, Iowa State University, Departments of Agronomy and Horticulture, Ames, IA 50011-1170
\end{abstract}

\section{Jeanine M. Davis \\ Mountain Horticultural Crops Research and Extension Center, North Carolina State University, 455 Research Drive, Fletcher, NC 28732}

\author{
James F. Hancock \\ Department of Horticulture, Michigan State University, East Lansing, MI 48824
}

Additional index words. medicinal plants, seed germination, plant selection and breeding

\begin{abstract}
Seed germination patterns were studied in Echinacea purpurea (L.) Moench grouped by seed source, one group of seven lots from commercially cultivated populations and a second group of nine lots regenerated from ex situ conserved wild populations. Germination tests were conducted in a growth chamber in light $\left(40 \mu \mathrm{mol} \cdot \mathrm{m}^{-2} \cdot \mathrm{s}^{-1}\right)$ or darkness at $25^{\circ} \mathrm{C}$ for 20 days after soaking the seeds in water for 10 minutes. Except for two seed lots from wild populations, better germination was observed for commercially cultivated populations in light (90\% mean among seed lots, ranging from $82 \%$ to $95 \%)$ and in darkness $(88 \%$ mean among seed lots, ranging from $82 \%$ to $97 \%)$ than for wild populations in light $(56 \%$ mean among seed lots, ranging from $9 \%$ to $92 \%)$ or in darkness $(37 \%$ mean among seed lots, ranging from $4 \%$ to $78 \%$ ). No germination difference was measured between treatments in light and darkness in the commercially cultivated populations, but significant differences were noted for treatments among wild populations. These results suggest that repeated cycles of sowing seeds during cultivation without treatments for dormancy release resulted in reduced seed dormancy in $E$. purpurea.
\end{abstract}

Echinacea, commonly known as purple coneflower, is a perennial, herbaceous plant native to eastern North America. A detailed morphological classification of Echinacea was provided by McGregor (1968) and recently revised by Binns et al. (2002) using morphological as well as numerical and statistical methods. According to McGregor (1968), there are 11 taxa in Echinacea including nine species and two botanical varieties.

Echinacea has long been used by Native

\begin{abstract}
Received for publication 18 Feb. 2005. Accepted for publication 14 May 2005. This publication is made possible by grant number 1R44AT771-01 from the National Center for Complementary and Alternative Medicine, by the Small Business Innovation Research program of the U.S. Department of Agriculture, grant number 2004-33610-14336, and by grant number P01 ES012020 from the National Institute of Environmental Health Sciences (NIEHS) and the Office of Dietary Supplements (ODS), NIH. Its contents are solely the responsibility of the authors and do not necessarily represent the official views of the NIEHS, NIH. Mention of commercial brand names does not constitute an endorsement of any product by the U.S. Department of Agriculture or cooperating agencies.

${ }^{1}$ To whom reprint requests should be addressed; e-mailx0w@gaiaherbs.com.
\end{abstract}

Americans for treating many conditions, including venomous bites, rabies, cold, headaches and stomach cramps (Foster, 1991; Kindscher, 1989; Li, 1998). In recent years, research results have demonstrated that Echinacea has immunostimulatory, antiviral, and antibacterial activities (Bauer and Wagner, 1991; Bodinet and Beuscher, 1991; Bodinet et al., 1993; Parnham, 1996).

Herbal products, made from the roots of $E$. angustifolia DC. and E. pallida (Nutt.) Nutt. and the roots and aerial parts of E. purpurea (L.) Moench, are among the most widely used herbal remedies in Europe and North America (Li, 1998). Increased market demand for Echinacea products has led to a rapid expansion of Echinacea cultivation worldwide (Li, 1998). Echinacea purpurea is the most used and cultivated species, accounting for $80 \%$ of Echinacea production (Li, 1998).

Seed propagation is the primary system for the establishment of new production fields of Echinacea. Wartidiningsih and Geneve (1994) reported erratic seed germination patterns in E. purpurea, with germination of non-treated seeds varying from $<40 \%$ to $>90 \%$ depending on seed lot. Methods used to overcome seed dormancy in E. purpurea have included cold-moist stratification, osmotic priming, and growth-regulator treatments (Parmenter et al., 1996; Pill et al., 1994; Pill and Haynes, 1996; Wartidiningsih et al., 1994).

Seed source, quality, and physiological maturity status may affect seed dormancy in $E$. purpurea (Wartidiningsih and Geneve, 1994). Among these factors, seed source could serve as a convenient and unambiguous indicator to help growers choose samples with minimal dormancy.

We found no dormancy in five lots of $E$. purpurea seeds from commercially cultivated sources (Qu et al., 2004). This suggested that repeated cycles of regeneration may have reduced or even eliminated seed dormancy in E. purpurea, as has been the case during the course of domestication of many other plant species (Copeland and McDonald, 1995; Harlan et al., 1973). However, because the seeds in that experiment (Qu et al., 2004) were stored dry under various temperature and humidity conditions for more than one year before testing, clear conclusions could not be drawn on the cause of this lack of dormancy. In a recent evaluation of untreated $E$. purpurea seeds harvested from commercially cultivated plants only a few months before testing, Qu et al. (unpublished data) also found no dormancy requirement.

Data on the variation of dormancy of seed lots from commercially cultivated populations or from wild stands have not been provided in previous reports on E. purpurea seed germination. Understanding differences in seed dormancy among various $E$. purpurea populations and determining the cause of dormancy reduction would be valuable, both in terms of the basic science (the genetics and evolution of this species) and in helping growers be more effective in selecting E. purpurea seeds. The objective of this investigation was to determine dormancy differences between E. purpurea seeds from commercially cultivated populations and from wild populations.

\section{Materials and Methods}

Echinacea purpurea seeds were grouped into two categories, those from commercially cultivated populations, presumably many generations removed from wild populations, and those from ex situ conserved wild populations. Commercially cultivated samples were purchased from seven seed companies (Ion Exchange, Harpers Ferry, Iowa; Johnny's Selected Seeds, Albion, Maine; Prairie Nursery, Westfield, Wis.; Prairie Moon Nursery, Winona, Minn.; Richters, Goodwood, Ontario, Canada; Stock Seed Farms, Murdock, Neb.; Wind River Seed, Manderson, Wyo.). Seeds from wild populations were provided by the U.S. Dept. of Agriculture-Agricultural Research Service, North Central Regional Plant Introduction Station (NCRPIS) in Ames, Iowa. Additional information for each seed lot is given in Table 1.

Germination tests of the seed lots were conducted in December 2003 under two treatment conditions, constant light and constant darkness. Each treatment consisted of three 
replications, 50 seeds per treatment for each lot from commercial sources and 16 seeds for each of the NCRPIS lots. The seed lots from the NCRPIS were retested in February 2004 with the same seed and replication numbers and treatment conditions. First, seeds were soaked in 50-mL beakers with about $20 \mathrm{~mL} \mathrm{de-}$ ionized water for $10 \mathrm{~min}$. After soaking, seeds were blotted dry on paper towels and placed in transparent plastic germination boxes $(11 \times 11$ $\times 3.5 \mathrm{~cm}$ ) on two layers of filter paper saturated with deionized water. The lids on the boxes then were sealed with Parafilm M (Pechiney Plastic Packaging, Menasha, Wis.). For the treatment in darkness, the germination boxes were wrapped with aluminum foil. Germination tests were conducted in a growth chamber (model 818; Precision, Winchester, Va.) at constant 25 ${ }^{\circ} \mathrm{C}$. Cool white fluorescent lamps mounted in the chamber door provided photosynthetically active radiation at $40 \mu \mathrm{mol} \cdot \mathrm{m}^{-2} \cdot \mathrm{s}^{-1}$. Germination (presence of radicles $>1 \mathrm{~mm}$ long) was recorded at four-day intervals for the treatment in light and two times (on days 12 and 20) for the treatment in darkness. The day-12 count for the treatment in darkness was conducted along with checking moisture level in the boxes, and it has been found that short exposure $(<1$ min) to light during germination evaluation had little effect on final germination (Qu et al, 2004). Germinated seeds were removed when counted, and the tests lasted for $20 \mathrm{~d}$ after initiation.

Each experiment was a completely randomized design. Since there were no significant differences between the two germination test results for the NCRPIS lots, those data were combined for final analysis. Germination percentages were normalized by transformation $(\arcsin \sqrt{ } \%)$ before being subjected to analysis of variance, following the methods of Wartidiningsih and Geneve (1994). Duncan's multiple range test was conducted on the transformed data after two-way ANOVA(seed lot $\times$ light vs. dark) to distinguish among individual lots.

\section{Results and Discussion}

Differences in seed germination were evident in the two groups (Table 1). Higher germination percentages were observed in commercial seed lots (90\% mean among seed lots in light, ranging from $82 \%$ to $95 \% ; 88 \%$ mean among seed lots in darkness, ranging from $82 \%$ to $97 \%$ ) than from the wild populations (56\% mean among seed lots in light, ranging from $9 \%$ to $92 \% ; 37 \%$ mean among seed lots in darkness, ranging from $4 \%$ to $78 \%$ ). For all but two populations (PI 633667 and PI 633669), seeds of the wild populations germinated significantly less frequently than did those of the commercially cultivated populations either in light or darkness.

Light vs. darkness during germination had no effect on germination percentage of commercially cultivated populations, but light increased the germination percentage of wild population (Table 1). Unpublished data from the NCRPIS (Widrlechner, personal communication) indicate that the differences observed in this experiment are, at least in part, if not entirely, due to the presence of dormancy in the wild populations. Seven of these nine seed lots from wild populations were tested for germination in February 2003 at the NCRPIS after using dormancy-breaking techniques involving ethephon and moist prechilling (modified from Sari et al., 2001), and all samples germinated within $21 \mathrm{~d}$ at levels between $70 \%$ and $95 \%$.

All commercial seed lots had similarly high germination percentages (Table 1) in darkness and light, indicating that dormancy was either absent or minimal. Previously, we reported that ethephon had little effect in promoting seed germination of $E$. purpurea seeds from other commercial sources (Qu et al., 2004), and we recently determined that seeds freshly harvested from plants grown from commercial seeds had no dormancy requirements $(92 \%$ to $98 \%$ germination) ( $\mathrm{Qu}$, unpublished data).

The history of cultivation of E. purpurea can help us understand the cause of the differences in germination behavior between these two groups of seeds. To learn more about the commercially cultivated seed samples, we communicated with technical personnel at the seed companies supplying the samples. Although it could not be confirmed with written records, the Echinacea plants used for commercial seed production were likely cultivated for more than ten generations, without dormancy-release treatments to increase germination. Available literature on the history of E. purpurea cultivation (Galambosi, 2004) indicates that much of the cultivated material was brought to Europe from wild populations in North America many years ago. We are aware

Table 1. Seed germination results of Echinacea purpurea from different seed lots.

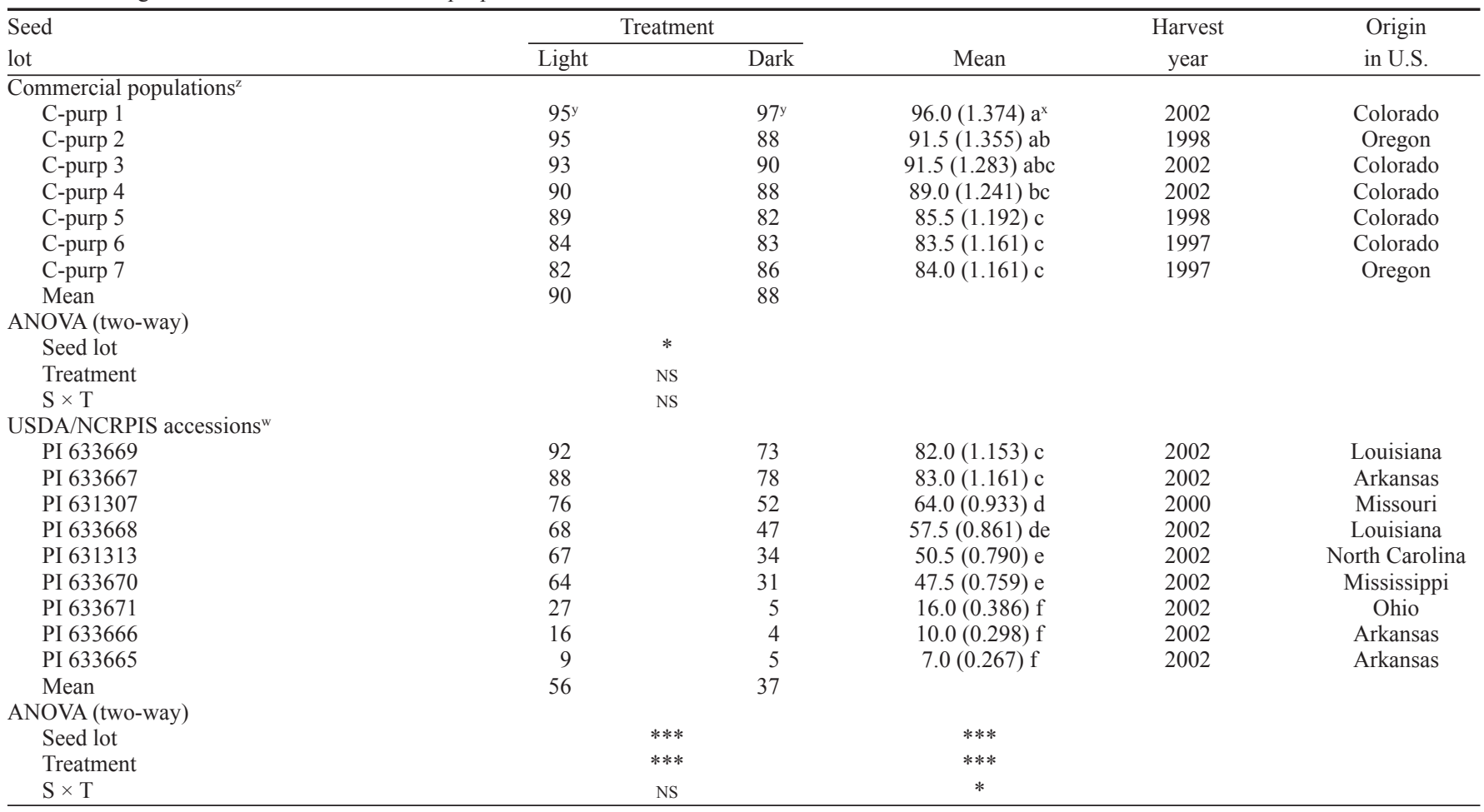

${ }^{{ }_{n}}=50$ seeds, three replications.

yPercentage.

${ }^{x}$ Mean separation within columns by Duncan's multiple range test after a combined analysis of transformed data representing all seed lots; transformed means (in parentheses) follow the untransformed data.

${ }^{w} n=32$ seeds, three replications.

NS,*****Nonsignificant or significant at $P<0.05$ or 0.0001 , respectively. 
of no publications or other types of information indicating that intentional selection to reduce seed dormancy has ever been conducted in Echinacea. However, our results indicate that a reduction or lack of dormancy in commercial E. purpurea populations is most likely due to unintentional selection during repeated cycles of cultivation.

In nature, Echinacea seeds fall to the ground in the autumn and overwinter in the soil. Before seeds germinate the following season, they may receive a moist chilling treatment, giving dormant and non-dormant seeds similar growth opportunities. But when seeds are harvested in the fall and stored in a dry state until sowing, nondormant seeds would germinate to a greater extent, and dormant seeds put at a selective disadvantage, since they would germinate more slowly if at all (Wartidiningsih et al., 1994).

The wild populations of E. purpurea conserved ex situ by the NCRPIS are maintained by regenerating them in screened field cages with pollinating insects (Widrlechner et al., 1997; Widrlechner and McKeown, 2002), in a manner designed to preserve the genetic integrity of individual populations (Wilson, 1989). Populations are established in the greenhouse by treating seeds with ethephon (Sari et al., 2001) so that selection for non-dormant types would be avoided. Given the geographic diversity of wild populations represented in our experiment (Table 1), dormancy may be a common phenomenon of E. purpurea in nature, although the levels may vary.

Germination percentage of the NCRPIS seed lots was higher in light than in dark (Table 1). A similar phenomenon has been noted for E. angustifolia (Feghahati and Reese, 1994; Qu et al., 2004). Previous authors (Qu et al., 2004; Smith-Jochum and Albrecht, 1987; Wartidiningsih and Geneve, 1994) have reported variable effects of light on seed germination in E. purpurea. Qu et al. (2004) suggested that while fully dormant Echinacea seeds could not germinate either in light or darkness, germination in light becomes possible with a partial release of dormancy. Differences in seed source and dormancy status may be responsible for observed variation in germination. In addition, since the seeds used in this study have all been stored in a dry state for more than one year, germination differences between the commercial and wild seed lots suggest that dry storage had minimal effect on seed dormancy.

Our results are the first to indicate that selection during cultivation may have unintentionally reduced seed dormancy in E. purpurea. However, we recognize that, by testing seed lots produced under various environmental conditions and by using commercial seed lots of unknown original parentage, our results must be considered preliminary. However, we believe the effects of these confounding factors to be relatively minor for the following reasons:

1) Seed dormancy is commonly a well-defined genetic characteristic that interacts with environmental variation (reviewed by Baskin and Baskin, 1998). In our judgment, the dif- ferences among environmental conditions at seed-regeneration sites or among seed-storage conditions used are small relative to genetic effects.

2) It is very difficult, if not impossible, to trace the original population(s) from which the commercially cultivated seed lots were produced. In the worst-case scenario, the commercial seeds may have been supplied from only two production fields, one in Oregon and the other in Colorado. However, these seed lots represent a substantial proportion of the E. purpurea seed used for commercial field production, since we obtained seeds from firms that are among the major suppliers. We expect that commercial seed lots do not trace back to only two production fields. We recently tested $E$. purpurea seed lots produced in California and Illinois, with germination results not significantly different (data not shown) from the commercial seed lots analyzed in this study.

Our results provide useful information for E. purpurea growers who wish to select populations for reduced seed dormancy. Since Echinacea seed production has not been standardized as it has for many other more established crops, we suggest germination tests to evaluate $E$. purpurea seed dormancy before sowing, even when seed source information has been provided.

The germination of two other species, $E$. angustifolia and E. pallida, widely cultivated as medicinal plants (Galambosi, 2004), has been reported to be more erratic than that of E. purpurea (Feghahati and Reese, 1994; Macchia et al., 2001; Qu et al., 2004; Shalaby et al., 1997; Sari et al., 2001), requiring the use of special dormancy-breaking protocols for consistent germination. It may be possible to duplicate the selection process for dormancy reduction in E. angustifolia and E. pallida by using multiple cycles of cultivation through untreated seed propagation, as has occurred in E. purpurea.

\section{Literature cited:}

Baskin, C.C. and J.M. Baskin. 1998. Seeds: Ecology, biogeography, and evolution of dormancy and germination. Academic Press, San Diego.

Bauer, R. and H. Wagner. 1991. Echinacea species as potential immunostimulatory drugs, $\mathrm{p}$. 253-321. In: H. Wagner and N.R. Farnsworth (eds.). Economic and medicinal plant research. vol. 5. Academic Press, London.

Binns, S.E., B.R. Baum, and J.T. Arnason. 2002. A taxonomic revision of Echinacea (Asteraceae: Heliantheae). Syst. Bot. 27:610-632.

Bodinet, C. and N. Beuscher. 1991. Antiviral and immunological activity of glycoproteins from Echinacea purpurea radix. Planta Medica 57:33-34.

Bodinet, C., I. Willigmann, and N. Beuscher. 1993. Host-resistance increasing activity of root extracts from Echinacea species. Planta Medica 59:672-673.

Copeland, L.O. and M.B. McDonald. 1995. Principles of seed science and technology. 3rd ed. Chapman \& Hall, New York

Feghahati, S.M.J. and R.N. Reese. 1994. Ethylene-, light-, and prechill-enhanced germination of Echinacea angustifolia seeds. J. Amer. Soc. Hort. Sci. 119:853-858.
Foster, S. 1991. Echinacea: Nature's immune enhancer. Healing Arts Press, Rochester, Vt.

Galambosi, B. 2004. Cultivation in Europe, p. 29-52. In: S.C. Miller and H. Yu (eds.). Echinacea: The genus Echinacea. CRC Press, Boca Raton, Fla.

Harlan, J.R., J.M.J. de Wet, and E.G. Price. 1973. Comparative evolution of cereals. Evolution 27:311-325.

Kindscher, K. 1989. Ethnobotany of purple conflower (Echinacea angustifolia, Asteraceae) and other Echinacea species. Econ. Bot. 43:498-507.

Li, T.S.C. 1998. Echinacea: Cultivation and medicinal value. HortTechnology 8:122-129.

Macchia, M., L.G. Angelini, and L. Ceccarini. 2001. Methods to overcome seed dormancy in Echinacea angustifolia DC. Scientia Hort. 89:317-324.

McGregor, R.L. 1968. The taxonomy of the genus Echinacea (Compositae). Univ. Kan. Sci.Bul. 48:113-142.

Parnham, M.J. 1996. Benefit-risk assessment of the squeezed sap of the purple coneflower (Echinacea purpurea) for long term oral immunostimulation. Phytomedicine 3:95-102.

Parmenter, G.A., L.C. Burton, and R. P. Littlejohn. 1996. Chilling requirement of commercial Echinacea seed. N.Z. J. Crop Hort. Sci. 24:109-114.

Pill, W.G., C.K. Crossan, J.J. Frett, and W.G. Smith. 1994. Matric and osmotic priming of Echinacea purpurea (L.) Moench seeds. Scientia Hort. 59:37-44.

Pill, W.G. and J.G. Haynes. 1996. Gibberellic acid during priming of Echinacea purpurea (L.) Moench seeds improves performance after seed storage. J. Hort. Sci. 71:287-295.

Qu, L., X. Wang, E. Hood, J. Yang, and R. Scalzo. 2004. Ethephon promotes germination of Echinacea angustifolia and E. pallida in darkness. HortScience 39:1101-1103.

Sari, A.O., M.R. Morales, and J.E. Simon. 2001. Ethephon can overcome seed dormancy and improve seed germination in purple coneflower species Echinacea angustifolia and E. pallida. HortTechnology 11:202-205.

Shalaby, A.S., E.A. Agina, S.E. El-Gengaihi, A.S. El-Khayat, and S.F. Hindawy. 1997. Response of Echinacea to some agricultural practices. J. Herbs, Spices Med. Plants 4(4):59-67.

Smith-Jochum, C.C. and M.L. Albrecht. 1987. Field establishment of three Echinacea species for commercial production. Acta Hort. 208:115-120.

Wartidiningsih, N. and R.L. Geneve. 1994. Seed source and quality influence germination in purple coneflower [Echinacea purpurea (L.) Moench.]. HortScience 29:1443-1444.

Wartidiningsih, N., R.L. Geneve, and S.T. Kester. 1994. Osmotic priming and chilling stratification improves seed germination of purple coneflower. HortScience 29:1445-1448.

Widrlechner, M.P., C.A. Abel, and R.L. Wilson. 1997. Ornamental seed production in field cages with insect pollination. Combined Proc. Intl. Plant Prop. Soc. 46:512-516.

Widrlechner, M.P. and K.A. McKeown. 2002. Assembling and characterizing a comprehensive Echinacea germplasm collection, p. 506-508. In: J. Janick and A. Whipkey (eds.). Trends in new crops and new uses. ASHS Press, Alexandria, Va.

Wilson, R.L. 1989. Minimizing extraneous transfer of sunflower pollen by honey bees (Hymenoptera: Apidae) in field cages. J. Kan. Ent. Soc. 62:387-391. 